\title{
Chemical differences between long and short amosite asbestos: differences in oxidation state and coordination sites of iron, detected by infrared spectroscopy
}

\author{
Andrew Graham, John Higinbotham, Doug Allan, Kenneth Donaldson, Paul H Beswick
}

\begin{abstract}
Objectives-Short fibres of amosite asbestos (SFA), obtained by ball milling of long fibres (LFA), have been shown to be less pathogenic than long fibres. Accumulating evidence suggests an important role for differences in surface chemistry between fibres. Iron has been implicated in the pathogenesis of asbestos fibres. In this study infrared (IR) spectroscopy was used to compare LFA and SFA in terms of the coordination and oxidation state of iron at the three cation sites $\left(M_{1}, M_{3}, M_{1}\right)$.

Methods - Infrared was used to examine LFA ad SFA, when dry and when hydrated in the presence and absence of the chelators desferroxamine and ferrozine. With appropriate software the proportions of iron and its oxidation states in the overlapping peaks were resolved and assigned, and the three coordination sites were identified. Data were obtained from 10 samples of both lengths of fibre for each of the four treatments. Iron release was also monitored.
\end{abstract}

Results-Iron was significantly more oxidised in LFA than SFA. Further oxidation of the dry fibres with water, ferrozine, or desferroxamine tended to abolish these differences. There were also significant differences between the proportions of iron held in the different coordination sites of the fibres. For LFA, a higher proportion of its iron was held in the cation sites coordinating less with iron and more with $\mathrm{Mg}$. Interestingly, the sites coordinating single irons were significantly more oxidised than multiple sites. The single iron sites were more oxidised in LFA than SFA and were more readily oxidised by the treatments.

Conclusions-Important chemical differences between LFA and SFA were found. There seemed to be some mobility of iron near the surface. Based on these data it is speculated that the 1 iron surface site may be important in pathogenesis. (Occup Environ Med 1999;56:606-611)

Keywords: asbestos; infrared spectroscopy; iron; amosite

The factors relating to fibre structure that determine their pathogenicity have been elucidated largely through the use of specially prepared fibre preparations. In particular, the systematic manipulation of fibre length has been used as a way to determine the part that fibre length plays in pathogenicity. For instance Wright and Kuschner ${ }^{1}$ showed that short fibres obtained by grinding caused less fibrosis in guinea pig lungs than the parent long fibres. These results have also been mimicked in vitro in several studies. For instance Brown et al showed that increasing length of fibres was associated with increasing biological activity in vitro as measured by two end points.

Two samples of amosite asbestos have been used extensively to provide data on the role of fibre length. These samples of long asbestos and the short sample that was derived from it by milling were used throughout the 1980s and into the 1990 s to show the role of fibre length in the pathology of asbestos. ${ }^{3}$ At equal airborne mass concentration, the long and short samples produced very different effects on the lung with the long sample being fibrogenic and carcinogenic whereas the short sample was not pathogenic. ${ }^{3}$ Donaldson et al then went on to use these samples as two models of fibres with differing pathogenicity which differed only in their length, to investigate the role of length in fibre pathogenicity at the cellular level. These studies showed that, compared with the short fibre sample, long fibre amosite was more inflammogenic, ${ }^{4}$ caused more epithelial detachment injury in vitro, ${ }^{5}$ more release of superoxide anion, ${ }^{6}$ and the cytokine tumour necrosis factor $(\mathrm{TNF})^{7}$ from exposed macrophages, and more chromosomal aberrations in exposed Chinese hamster ovary cells. ${ }^{8}$

The importance of this accumulating database on the biological activity of these two samples of asbestos has lain in the argument that the two samples differed only in their length and that there were no differences in chemistry, and by implication, in the surface reactivity of the two samples. Recently however, in the course of studies on the surface activity of the short and long samples we have found that the short and long amosite samples do differ in three different ways. The long amosite samples bound more protein, had more free radical activity, and released more iron than the short amosite samples, despite the short fibres having a much greater surface area. ${ }^{9}{ }^{10}$ Wylie et al in 1997 concluded that fibre dimensions or surface area could not account for the proliferative response of cells to talc and asbestos, and that composition was therefore important. $^{11}$ 
A

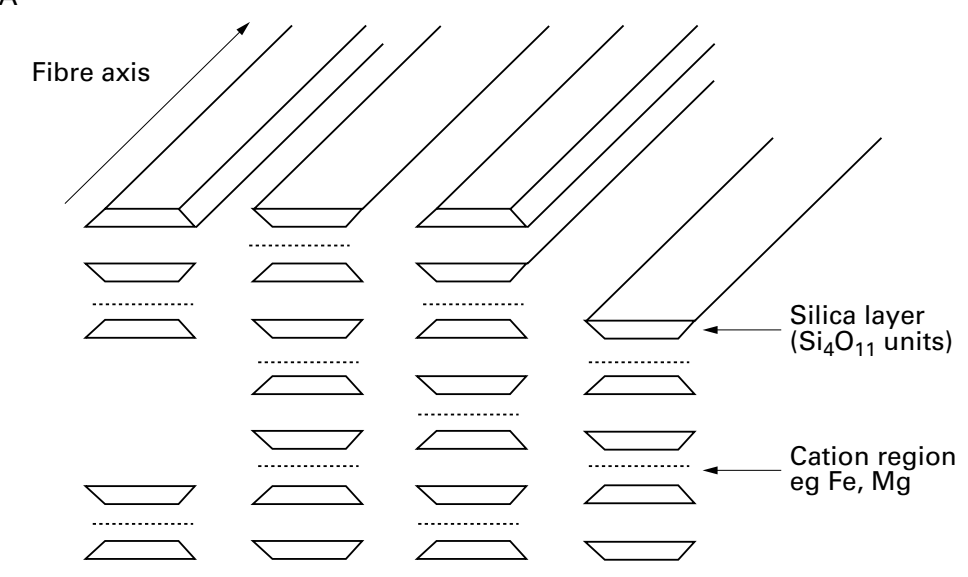

B

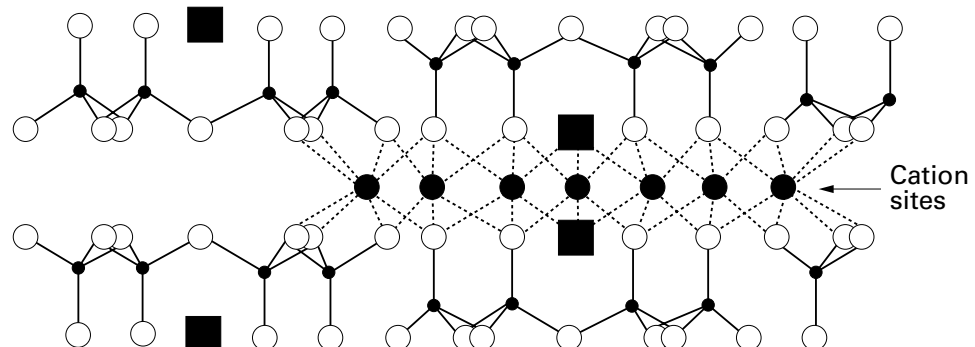

Fibre axis is into the page

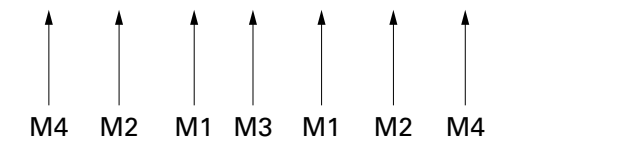

Referring to cation sites

Figure 1 Structural details of amphibole asbestos. (A) The idealised structure is composed of double chains of linked silica tetrahedra, which form a silica layer. (B) These layers are cross linked with seven bridging cations, which form the core of the unit cell. Three sites $\left(M_{1}, M_{3}, M_{1}\right)$ interact with the hydroxyl group and can be detected with infrared spectroscopy.

About one third of the mass of amosite fibres comprises iron ${ }^{12}$ and reactions due to the surface iron are increasingly being invoked as causing asbestos related damage, both in vitro and in vivo, and the role of iron in the generation of free radicals has been strongly suspected. ${ }^{9}{ }^{13-15}$ The simple presence of ferrous ions engaging in Fenton chemistry is not sufficient to explain the important chemistry of damaging reactions. Ferric ions are particularly implicated by several authors. ${ }^{15-17}$ According to Fubini and Mollo, "Only a small fraction of the ions in a well defined co-ordination and redox state, appear involved in the toxicity of mineral dust". ${ }^{15}$ If iron's role is crucial to toxicity and short amosite fibres are substantially less toxic than the long fibres and fibre length is not a determinant, then differences in the nature of the iron need to be investigated.

We show here data from infrared spectroscopy that shed further light on differences between the two samples. Infrared spectroscopy is a powerful analytical tool, which can be used to study molecular vibrations. It can show the structure, atomic interaction, and bond types present within molecules. It has been used to identify types of asbestos, ${ }^{18}$ to gain information about the cation distribution between coordination sites ${ }^{12}$ and to examine interactions between asbestos and protein. ${ }^{19}$ The idealised amphibole asbestos structure is composed of double chains of linked silica tetrahedra, which form a silica layer. These layers are cross linked with seven bridging cations as can be seen in figure 1 . These cations alter the interplanar spacings and can affect the angle at which the adjacent layers are stacked. Finer structural details of the silica and cation layers are also shown in figure 1. Although there are seven cations, there are only four distinct sites $\left(M_{1}\right.$ to $\left.M_{4}\right)$, due to symmetry of the cations about the central cation $\left(M_{3}\right)$. Only $M_{1}$ and $M_{3}$ (in two sites) interact with the hydroxyl group. These three sites $\left(\mathrm{M}_{1}, \mathrm{M}_{3}, \mathrm{M}_{1}\right)$ are coordinated to four oxygen atoms (each one attached to one silicon) and two hydroxyl groups. We conducted an investigation into short and long fibre amosite centred around the coordination of the three cation sites $\left(M_{1}\right.$, $M_{3}, M_{1}$ ) in the neighbourhood of the hydroxyl group. Overlapping absorbance peaks are produced, depending on the type of cation $(\mathrm{Mg}$, $\mathrm{Fe})$ and valency $\left(\mathrm{Fe}^{2+}, \mathrm{Fe}^{3+}\right)$ present. ${ }^{12}$ Properties such as oxidation state and the nature of the coordination of the iron were monitored in the long and short amosite samples in their native form and after various treatments including iron chelators.

\section{Materials and methods}

Samples of short (SFA) and long fibre amosite (LFA) were supplied by the Canadian Asbestos Institute (fig 2). ${ }^{349} \mathrm{~A}$ total of 80 samples of LFA and SFA (1 mg) had no treatment, or were treated with either $2 \mathrm{ml}$ distilled water or $2 \mathrm{ml} 4 \mathrm{mM}$ ferrozine $\left(\mathrm{Fe}^{2+}\right)$ or desferrioxamine $\left(\mathrm{Fe}^{3+}\right)$ specific iron chelators in citrate/ phosphate buffer ( $\mathrm{pH} 4.6$ ). The buffer contained $42.4 \mathrm{mM}$ citric acid and $75.2 \mathrm{mM}$ $\mathrm{Na}_{2} \mathrm{HPO}_{4}$. Therefore, there were 10 samples for each treatment of each fibre. These were placed in a rotating incubator at $37^{\circ} \mathrm{C}$ for 24 hours, the fibres were then removed by centrifugation at $4000 \mathrm{rpm}$ for 10 minutes. The supernatant was removed and examined for iron content with the Beckman DU 7500 diode array spectrometer at 562 and $430 \mathrm{~nm}$ for ferrous and ferric iron respectively; the fibres were washed in $2 \mathrm{ml}$ distilled water, vortexed for 10 seconds and again spun down, this process was repeated three times. The fibres were dried, encapsulated into $\mathrm{KBr}$ discs and dried in a vacuum oven at $120^{\circ} \mathrm{C}$ for 3 hours. The discs were prepared by mixing the amosite sample with dry powdered $\mathrm{KBr}$ and pressing under high pressure in an evacuated die to produce a thin clear disc. The $\mathrm{KBr}$ to sample weight ratio was typically 100:1. A Perkin Elmer 811 dual 

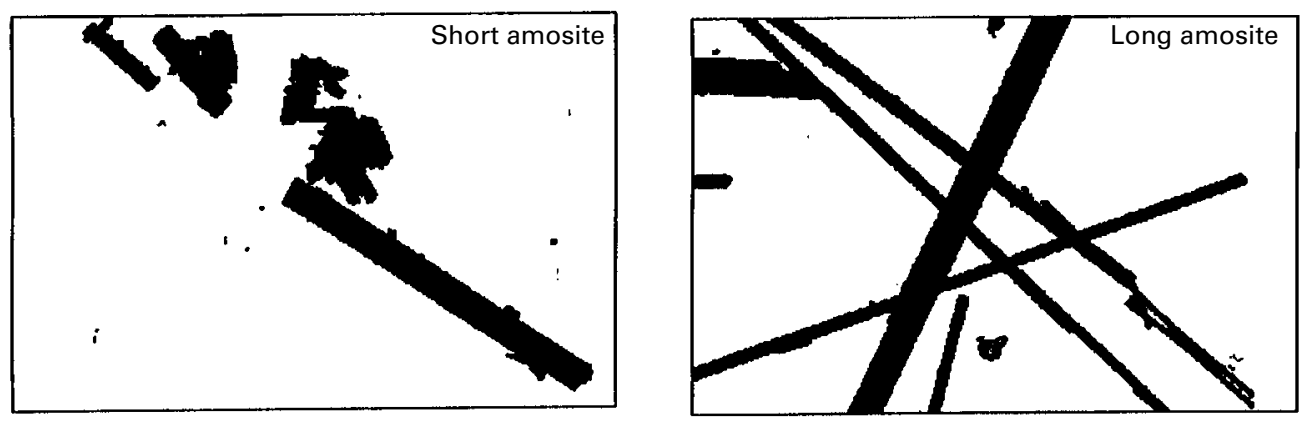

$2 \mu \mathrm{m}$

Figure 2 Scanned TEM images of long fibre amosite (LFA) and short fibre amosite (SFA). Note that of the 20 or so particles of SFA, mostly clumped, only one fulfils the WHO criteria for a fibre $(>5 \mu \mathrm{m}$ long, $<3$ um wide, aspect ratio $>3: 1$ ). All of the seven fibres of LFA fulfilled the WHO criteria, although the ends of the fibres cannot be seen in this image.

beam spectrophotometer was purged with an air drier $(50 \mathrm{l} / \mathrm{min})$, and samples were scanned 200 times, to improve the signal to noise ratio.

Resolving the overlapping absorbance peaks into individual components was achieved with Jandel Scientific's Peakfit software. These results can be seen for a typical example of LFA in figure 3. The peaks were assigned as in table 1. Luys et $a l^{12}$ have previously assigned the bulk iron peaks without resolving the peaks for oxidation states. We were able to resolve and assign the oxidation states of these peaks, as the change in oxidation state shifts the peak maxima by about $5 \mathrm{~cm}^{-1}$. The software used allowed this resolution. Variations in sample preparations meant that absolute iron content could not be assessed, but peak area ratios yielded valuable information. Examination of data was performed with Minitab's analysis of variance (ANOVA) for balanced designs, where ratios of the areas of peaks within each sample type were used for comparison of long versus short fibre amosite, and also for the effects of the various treatments. Data were analysed with two sample $t$ tests assuming unequal variance and ANOVA to examine main effects, residuals, and interactions. Interpretation of the data was performed with a combination of both techniques.

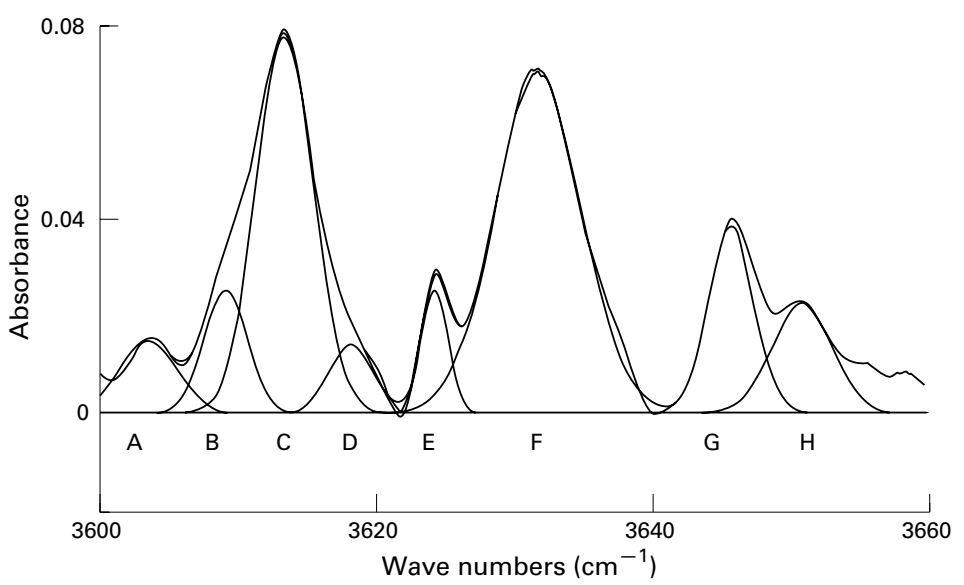

Figure 3 Resolution of the overlapping peaks with the Peakfit curve fitting software package. The peaks (lettered $A$ to $H$ ) are shown as having been resolved from the data points representing the overlapping peaks.

\section{Results}

The data presented here are not based on direct comparisons of single measurements of LFA and SFA. This was not possible because of the practical difficulties of creating exact sample replicates. Therefore, we have examined the ratios of deconvoluted peak areas where uniformity was obtained. To do this with statistical relevance, 10 samples for each treatment of each fibre were studied to gain a clearer picture of the extent of these variations. Much information may be obtained from this type of analysis. A typical range of spectral absorbances for long and short fibre amosite have been selected from all the results and is shown in figure 4 . As can be seen, only small variations occur within SFA, whereas more notable differences appear in LFA. Examination of the resolved absorbance spectra shows the presence of several small peaks associated with the main peaks. The ions located at the three cation coordination sites $\left(M_{1}, M_{3}, M_{1}\right)$ are described by these peaks in table 1 . We refer to this as site occupancy. We were able to calculate the depth of penetration of infrared energy into the amosite fibres, taking account of scattering by amosite and $\mathrm{KBr}$, absorption by amosite, and also of reflection from the proximal and distal surfaces of the sample. Use was made of the fact that absorption of infrared energy by amosite is the only one of these phenomena that causes a dramatic effect at specific wave numbers within the scan range. The linear absorption coefficient for amosite was found to be 11.1 (1.6) $\mathrm{mm}^{-1}$ and thus the depth

Table 1 Occupation of the three cation co-ordination sites $\left(M_{1} M_{3} M_{\nu}\right)$ for amosite samples. Note that the three cations shown within any peak can be in any one of three cation orders - for example, in peak $\mathrm{A}$, the $\mathrm{Fe}^{2+}$ cation can be in either of the two $M_{1}$ positions, or the $M_{3}$ position

\begin{tabular}{lll}
$\begin{array}{l}\text { Co-ordination site peak } \\
\text { (from fig 3) }\end{array}$ & $M_{1}, M_{3}, M_{1}$ occupation & Iron quantity \\
\hline A & $\mathrm{Fe}^{2+}, \mathrm{Fe}^{3+}, \mathrm{Fe}^{3+}$ & 3 \\
B & $\mathrm{Fe}^{2+}, \mathrm{Fe}^{2+}, \mathrm{Fe}^{3+}$ & 3 \\
C & $\mathrm{Fe}^{2+}, \mathrm{Fe}^{2+}, \mathrm{Fe}^{2+}$ & 3 \\
D & $\mathrm{Fe}^{3+}, \mathrm{Fe}^{3+}, \mathrm{Mg}^{2+}$ & 2 \\
E & $\mathrm{Fe}^{2+}, \mathrm{Fe}^{3+}, \mathrm{Mg}^{2+}$ & 2 \\
F & $\mathrm{Fe}^{2+}, \mathrm{Fe}^{2+}, \mathrm{Mg}^{2+}$ & 2 \\
G & $\mathrm{Fe}^{3+}, \mathrm{Mg}^{2+}, \mathrm{Mg}^{2+}$ & 1 \\
H & $\mathrm{Fe}^{2+}, \mathrm{Mg}^{2+}, \mathrm{Mg}^{2+}$ & 1 \\
\hline
\end{tabular}




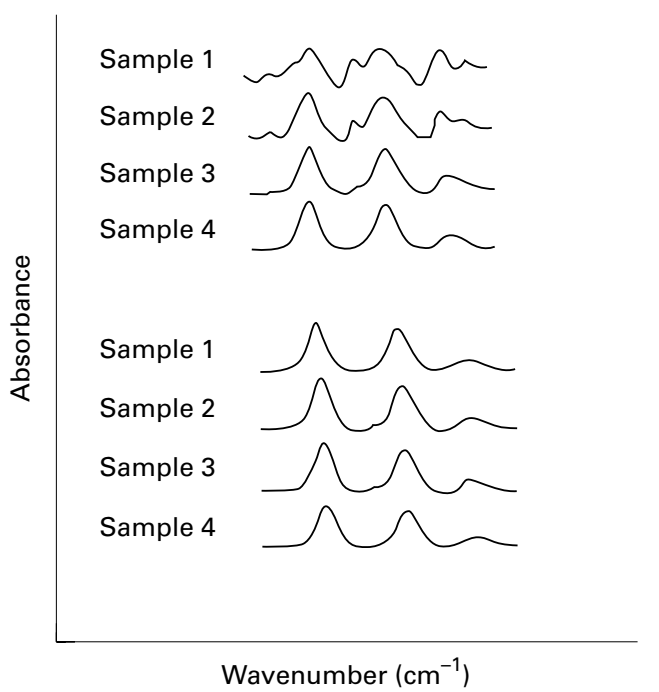

Figure 4 Spectral variations within long and short fibre amosite asbestos. The examples selected represent the range of variation within each type of fibre, with most spectral responses lying between samples 2 and 3 for LFA; SFA produces very little spectral variation.

of penetration at which the energy fell to $36.8 \%$ (the fraction $\mathrm{e}^{-1}$ ) was $90(13) \mu \mathrm{m}$. This is significantly larger than the diameter of a typical fibre $(0.2 \mu \mathrm{m})$, so it can be assumed that the data obtained reflect the total iron of the samples in the $M_{1}$ and $M_{3}$ coordination sites and are not skewed by surface effects.

A comparison of $\mathrm{Fe}^{2+} / \mathrm{Fe}^{3+}$ peak ratios, with significant differences between LFA and SFA, is given in table 2. The results show that for both fibres, the bulk of the iron was in the reduced state $\left(\mathrm{Fe}^{2+}\right)$ although the two fibres are significantly different; the reduced iron representing $89.8 \%$ of the total for LFA and $83.9 \%$ of the total for LFA $(p \leqslant 0.01)$. The iron bound at the 1 iron site had a far greater proportion of iron in the oxidised form than at the other sites. Long fibre amosite had a greater proportion of iron in the oxidised state than SFA at all the co-ordination sites. Table 3 shows the relation between the iron content of the coordination sites. Significant differences between SFA and LFA are apparent. Most of the iron was held in the 2 iron and 3 iron sites for both SFA and LFA although significantly less iron was held in the 2 iron sites than the 3 iron sites in SFA than LFA. This was true for $\mathrm{Fe}^{2+}, \mathrm{Fe}^{3+}$, and total iron. Although the least iron was found in the 1 iron sites for both SFA and LFA, significantly less $\mathrm{Fe}^{2+}$ and total iron was found in these sites in SFA than LFA. Therefore, overall, the iron in LFA tended to occupy the lower occupancy sites more than was the case for SFA.

Table 2 Comparison of $\mathrm{Fe}^{2+} / \mathrm{Fe}^{3+}$ ratios between SFA and LFA (both types of fibre are untreated)

\begin{tabular}{llll}
\hline Iron sites & SFA & LFA & 95\% CI \\
\hline Total iron & 8.77 & 5.21 & 1.51 to $5.61^{\star}$ \\
1 & 1.62 & 1.53 & -0.60 to 0.78 \\
2 & 15.63 & 8.26 & 2.74 to $10.4^{\star}$ \\
3 & 13.15 & 8.47 & -1.49 to 10.9 \\
\hline
\end{tabular}

Results are means of 10 samples of each fibre.

${ }^{\star} \mathrm{p}<0.05$ for total iron (sum total of the 1,2 , and 3 iron sites), and also individually for the 2 and 3 iron sites.
Table 3 Comparison of site occupancy of iron between the untreated fibre types of LFA and SFA

\begin{tabular}{lllll}
\hline Iron & $\begin{array}{l}\text { Ratio of site } \\
\text { occupancy }\end{array}$ & SFA & LFA & 95\% CI \\
\hline Total iron & $1: 2$ & 0.276 & 0.437 & 0.70 to $0.25^{\star}$ \\
& $1: 3$ & 0.273 & 0.490 & 0.13 to $0.03^{\star}$ \\
$\mathrm{Fe}^{2+}$ & $2: 3$ & 0.987 & 1.132 & 0.10 to $0.18^{\star}$ \\
& $1: 2$ & 0.185 & 0.294 & 0.60 to $0.15^{\star}$ \\
$\mathrm{Fe}^{3+}$ & $1: 3$ & 0.185 & 0.332 & 0.09 to $0.20^{\star}$ \\
& $2: 3$ & 0.997 & 1.121 & 0.09 to $0.16^{\star}$ \\
& $1: 2$ & 1.818 & 1.630 & -0.37 to 0.74 \\
& $1: 3$ & 1.516 & 2.187 & -0.02 to 1.36 \\
& $2: 3$ & 0.872 & 1.457 & 0.14 to $1.03^{\star}$
\end{tabular}

Results are means of 10 samples of each fibre.

${ }^{\star} \mathrm{p}<0.05$ for total iron content and for $\mathrm{Fe}^{2+}$ alone, $v$ all three ratios of site occupancy. Only the ratio of the 2:3 site occupancy is significant for $\mathrm{Fe}^{3+}$.

Experiments were conducted to determine the effects of water, the $\mathrm{Fe}^{2+}$ chelator ferrozine, and the $\mathrm{Fe}^{3+}$ chelator desferrioxamine on the oxidation states and the occupation of coordination sites by iron. The oxidation of iron by the various treatments is shown in table 4 , with the results being expressed as the percentage of the total iron in the $\mathrm{Fe}^{3+}$ form. In view of these results, describing the oxidation state of the total detected material, much of the oxidation is probably represented by surface oxidation. A feature of these results is that water alone significantly oxidised the iron at all coordination sites in SFA but only at the 1 iron site in LFA. Indeed the 1 iron site which contains the least iron and in the most oxidised form, was the site that seemed to be substantially more susceptible to oxidation in both fibres. After all the treatments, the degree of oxidation of the SFA was similar to the LFA before treatment (table 4). Desferrioxamine solutions caused oxidation of the iron at all sites to a greater extent than water alone. The results for ferrozine were only greater than water at some sites. This is probably a reflection of the chelated iron being more susceptible to oxidation in an aqueous environment.

Results of experiments to determine whether water and chelators could change the relative occupation of the coordination sites are shown in table 5 . The results show the relation of iron in the 1 iron site to the 3 iron site. For SFA, for all treatments, the iron content, both $\mathrm{Fe}^{2+}$ and $\mathrm{Fe}^{3+}$, shifted from the 3 iron site to the 1 iron site. This was most marked for $\mathrm{Fe}^{3+}$. No real difference was found between the treatments. This shift was only seen with the water treatment in LFA for $\mathrm{Fe}^{3+}$. The SFA, when treated with water, ferrozine, or desferrioxamine became similar to untreated LFA for the same variable.

Measurements of the iron content of the solutions used to treat the fibres were made. Negligible iron was released when the fibres were immersed in distilled water. With ferrozine, the iron $\left(\mathrm{Fe}^{2+}\right)$ leached was 34.2 (3.1) $\mathrm{nmol} / \mathrm{mg}$ for SFA and $47.0(4.8) \mathrm{nmol} / \mathrm{mg}$ for LFA. With desferroxamine the iron $\left(\mathrm{Fe}^{3+}\right)$ leached was 753 (57) $\mathrm{nmol} / \mathrm{mg}$ for SFA and 261 (34) $\mathrm{nmol} / \mathrm{mg}$ for LFA. 
Table 4 Oxidation of iron due to various treatments (\% in $\mathrm{Fe}^{3+}$ form)

\begin{tabular}{lrlll}
\hline $\begin{array}{l}\text { Fibre type and } \\
\text { iron site }\end{array}$ & Dry & Water & Ferrozine & DSF \\
\hline $\begin{array}{l}\text { SFA: } \\
\quad \text { Total iron }\end{array}$ & 10.2 & $15.5\left(1.8\right.$ to $\left.26.0^{\star}\right)$ & $15.2\left(2.8\right.$ to $\left.7.0^{\star}\right)$ & $19.1\left(3.3\right.$ to $\left.6.3^{\star}\right)$ \\
$\quad 1$ & 38.2 & $55.1\left(3.7\right.$ to $\left.9.6^{\star}\right)$ & $50.5\left(0.6\right.$ to $\left.9.0^{\star}\right)$ & $57.2\left(5.1\right.$ to $\left.15.3^{\star}\right)$ \\
$\quad 2$ & 7.0 & $9.3\left(0.8\right.$ to $\left.1.5^{\star}\right)$ & $9.8\left(0.8\right.$ to $\left.1.8^{\star}\right)$ & $11.9\left(1.9\right.$ to $\left.3.4^{\star}\right)$ \\
LFA: & & & & \\
$\quad$ Total iron & 16.1 & $16.2(-0.03$ to 0.03$)$ & $22.5\left(0.9\right.$ to $\left.3.5^{\star}\right)$ & $19.8(-0.15$ to 1.9$)$ \\
1 & 39.5 & $59.5\left(7.1\right.$ to $\left.15.2^{\star}\right)$ & $59.2\left(5.0\right.$ to $\left.16.0^{\star}\right)$ & $51.1\left(1.7\right.$ to $\left.7.2^{\star}\right)$ \\
2 & 10.8 & $9.1(-0.17$ to 0.85$)$ & $15.0\left(0.3\right.$ to $\left.2.2^{\star}\right)$ & $13.6\left(0.18\right.$ to $\left.1.2^{\star}\right)$ \\
\hline
\end{tabular}

Results are means (95\% CIs) of 10 samples of each fibre for each treatment.

${ }^{\star} \mathrm{p}<0.05$ Oxidation of iron in SFA for all treatments $v$ untreated for total iron (iron in sites 1,2 , and 3), and also individually for the 1 and 2 iron sites. However, $p<0.05$ oxidation of iron in LFA is significant for all treatments only in the 1 iron site.

Table 5 Effects of treatments on iron occupation of 1 iron and 3 iron sites, expressed as a ratio of iron in 1 iron sites to iron in 3 iron sites

\begin{tabular}{lllll}
\hline $\begin{array}{l}\text { Fibre type and } \\
\text { iron site }\end{array}$ & Dry & Water & Ferrozine & DSF \\
\hline $\begin{array}{l}\text { SFA: } \\
\text { Total iron }\end{array}$ & 0.27 & $0.46\left(0.14\right.$ to $\left.0.24^{\star}\right)$ & $0.44\left(0.09\right.$ to $\left.0.25^{\star}\right)$ & $0.50\left(0.14\right.$ to $\left.0.32^{\star}\right)$ \\
$\mathrm{Fe}^{2+}$ & 0.19 & $0.22(0.00$ to 0.08$)$ & $0.25\left(0.01\right.$ to $\left.0.13^{\star}\right)$ & $0.25\left(0.01\right.$ to $\left.0.13^{\star}\right)$ \\
$\quad \mathrm{Fe}^{3+}$ & 1.52 & $5.48\left(2.14\right.$ to $\left.5.78^{\star}\right)$ & $3.45\left(0.65\right.$ to $\left.3.21^{\star}\right)$ & $3.20\left(1.03\right.$ to $\left.2.31^{\star}\right)$ \\
$\begin{array}{l}\text { LFA: } \\
\text { Total iron }\end{array}$ & 0.49 & $0.41(-0.01$ to 0.19$)$ & $0.48(-0.09$ to 0.11$)$ & $0.43(-0.04$ to 0.16$)$ \\
$\mathrm{Fe}^{2+}$ & 0.33 & $0.18\left(0.09\right.$ to $\left.0.21^{\star}\right)$ & $0.25(0.00$ to 0.16$)$ & $0.24\left(0.03\right.$ to $\left.0.15^{\star}\right)$ \\
$\mathrm{Fe}^{3+}$ & 2.19 & $3.60\left(0.26\right.$ to $\left.2.02^{\star}\right)$ & $1.78(-0.27$ to 1.09$)$ & $1.73(-0.24$ to 1.16$)$ \\
\hline
\end{tabular}

Results are means (95\% CIs) of 10 samples of each fibre for each treatment.

${ }^{\star} \mathrm{p}<0.05$ For SFA in each of the treatments $v$ untreated, increases in the ratio of iron in the 1 iron sites to iron in the 3 iron sites for total iron (both $\mathrm{Fe}^{2+}$ and $\mathrm{Fe}^{3+}$ ) and individually for $\mathrm{Fe}^{3+}$ in each of the treatments. For LFA, the ratios decrease in magnitude for $\mathrm{Fe}^{2+}$ (for water and DSF treatments), and significantly increase for $\mathrm{Fe}^{3+}$ when treated with water.

\section{Discussion}

The data presented here represent the first direct evidence of molecular differences between SFA and LFA samples. Furthermore these differences may have important implications for the relative toxicity of the two samples. Our data add to the other chemical information aimed at elucidating the exact mechanisms of fibre pathogenicity. ${ }^{14}$ We have previously implicated fibre length as the only explanatory variable for the difference in pathogenicity between the long and short amosite samples. ${ }^{3}$ However, there are accumulated data showing differences in the surface of the long and short samples that cannot be explained by surface area. Although the fibre diameter remains the same for both samples, surface area of SFA is greater than LFA because of the ends and shards produced by ball milling. The differences in fibre surface characteristics evident biochemically and now at the molecular level could be important factors in making the long amosite more pathogenic.

Other studies suggest that surface chemistry may be a another factor as well as fibre length and diameter that could modify the pathogenic potency of fibres. Erionite is a fibre that was found to be more potently pathogenic than any other fibre in causing mesotheliomas. ${ }^{20}$ These fibres were not particularly long and so chemistry of the surface has been suggested as a factor in pathogenic potency of erionite. Also, Monchaux et al have shown that treating chrysotile under acid conditions which did not change the fibre number or length, changed the ability of the fibres to cause mesothelioma compared with untreated fibres. ${ }^{21}$ Once again it is possible to conclude that the treatment has altered the surface chemistry of the fibres. Brown et al modified the surface of amosite asbestos with different long chain fatty acids and changed the ability of the fibres to cause mesothelioma. ${ }^{22}$ In vitro it is relatively easy to alter the biological activity of fibres by treating them with proteins that coat their surfaces. ${ }^{63}$

The infrared spectroscopy confirms that there are profound differences in surface iron chemistry between the SFA and LFA at the molecular level. In both LFA and SFA, $>80 \%$ of the total detected iron was in the reduced form but a significantly greater proportion of the iron in LFA was oxidised. Such differences in the structures of fibre surfaces could be a result of the high stresses imposed on the fibres by the ball milling process. ${ }^{24}$ Ghio et al showed that surface $\mathrm{Fe}^{3+}$ was a determinant of free radical damage. ${ }^{17}$ As our method detected the total $M_{1}, M_{3}, M_{1}$ iron, then the greater oxidation of the LFA is probably understated for the surface. A further finding is that the 1 iron site had a far greater proportion of the iron as ferric iron than the 2 iron and 3 iron coordination sites. By coulometric means, Shen et al showed that for amosite, $75 \%$ of the available redox active surface iron was oxidised. Furthermore, they found that the total accessible redox active iron was only $3.6 \mathrm{nmol} / \mathrm{mg}$ for amosite. ${ }^{25}$

Further differences between LFA and SFA were found when comparisons between coordination sites were examined. There tends to be a lower proportion of iron in the multiple occupancy (2 or 3) co-ordination sites of LFA, than SFA. This is true for total, ferrous, and ferric iron although the results for ferric iron are less significant due to the lower concentrations of $\mathrm{Fe}^{3+}$. We provide evidence to indicate that the addition of distilled water to the amosite asbestos samples causes surface oxidation of ferrous to ferric iron. The effect of leaching the surface with either desferrioxamine or ferrozine in conjunction with a citrate/ phosphate buffer ( $\mathrm{pH}$ 4.6) was to significantly increase the proportion of ferric relative to ferrous iron. This could be due to either preferential ferrous iron mobilisation from the surface into solution, or oxidation of ferrous to ferric iron on the surface, or a combination of the two. The fact that little iron seemed to be leached into distilled water suggests that the oxidation of ferrous to ferric iron on the surface is the more important. It seems that water is more important than the chelators in changing the oxidation status of the fibre surfaces. This has implications for the interpretation of chelator studies. This increase in the oxidation of the bulk material, shown by infrared spectroscopy could not be shown with Mossbauer spectroscopy. ${ }^{16}$

During oxidation by water or the chelator solutions there was a shift in the proportions of iron coordinated at the various sites. The shift in all cases, where significant, was to increase the proportion of iron in the 1 iron site, the changes were greatest for iron in its oxidised form.

There is some evidence that outer layers of amosite fibres have a greater abundance of 1 iron coordination sites than is found inside the 
fibres. A simple calculation based on a typically sized fibre and a knowledge, from atomic dimensions, of the number of silica layers and cation regions across a fibre, allows us to determine that $9 \%$ of the iron examined is in the outer layer of cation sites. As it is the outer layer which is, or becomes oxidised by the treatments, then the data we have where, for LFA, $10 \%$ of the iron is in the oxidised form fit well with the calculation. However, when we examined the 1 iron site, $38.2 \%$ of the iron was oxidised and this increased to $57.2 \%$ on treatment with water. It is reasonable to conclude that the 1 iron sites tend to be on the surface of the fibre, unlike the 2 iron and 3 iron coordination sites.

Consideration of the iron content of the supernatant removed from the samples, showed that distilled water oxidised ferrous iron on the surface of the fibres, but cannot mobilise it into solution. The two leachants, however, do result in mobilisation of iron from the surface, and the significantly higher levels of ferric iron detected may be due to oxidation of the ferrous iron before or after mobilisation has taken place.

It is tempting to speculate that the 1 iron coordination site may be important in the damaging processes brought about by amosite. It is the most oxidised of the sites and the site most able to change its oxidation state which supports the contention that it has a surface position and this form of iron is significantly more prevalent in LFA than in SFA. The treatments of the amosite seem to be able to shift iron to this form from the other coordination forms. There may be a link between the oxidised redoxactive iron, ${ }^{25}$ the distinctive reaction sites described by Fubini et al, ${ }^{14}$ the supposition of Gold et al that iron mobility in the silicate structure may be very important in chemical reactivity, and the 1 iron coordination site. ${ }^{16}$ Further work to elucidate the nature of the reactive sites will be required.

More generally, this study highlights the potential pitfalls of using milled or ground samples of particles. Such samples may have pathologically relevant differences in their surface chemistry, compared with the parent sample.

This work was supported in part by the Health and Safety Executive, United Kingdom.

1 Wright G, Kuschner M. The influence of varying lengths of glass and asbestos fibers on tissue responses in the guinea pigs. In: Walton WH, ed. Inhaled Particles IV Oxford: Pergamon Press, 1977:455-74.

2 Brown GM, Cowie H, Davis JMG, et al. In vitro assays for detecting carcinogenic mineral fibres: a comparison of two assays and the role of fibre size. Carcinogenesis 1986;7: 1971-4.
3 Davis JG, Addison J, Bolton RE, et al. The pathogenicity of long versus short fiber samples of amosite asbestos adminstered to rats by inhalation and intraperitoneal injection. British fournal Of Experimental Pathology 1986;67:415-30.

4 Donaldson K, Brown GM, Brown DM, et al. Inflammation generating potential of long and short fiber amosite asbestos samples. Br F Ind Med 1989;46:271-6.

5 Donaldson K, Miller BG, Sara E, et al. Asbestos fiber length-dependent detachment injury to alveolar epithelialcells in vitro: role of a fibronectin-binding receptor. Int 7 Exp Pathol 1993;74:243-50.

6 Hill IM, Beswick PH, Donaldson K. Differential release of superoxide anion by macrophages treated with long and short amosite asbestos is a consequence of differential affinity for opsonin. Occup Environ Med 1995;52:92-6.

7 Donaldson K, Li XY, Dogra S, et al. Asbestos-stimulated tumor-necrosis-factor release from alveolar macrophages depends on fiber length and opsonization. I Pathol 1992; 168:243-8.

8 Donaldson K, Golyasnya N. Long and short amosite asbestos: comparison of chromosome-damaging effects to cells in culture with in vivo pathology. In: JMG Davis, MC Jaurand, eds. Cellular and molecular effects of mineral and synthetic dusts and fibres. Berlin: Springer Verlag, 1994: $221-6$.

9 Gilmour PS, Beswick PH, Brown DM, et al. Detection of surface free radical activity of respirable industrial fibres using fX174RF1 plasmid DNA. Carcinogenesis 1995;16: using fX17.

10 Hill IM, Beswick PH, Donaldson K. Enhancement of the macrophage oxidative burst by IgG coating of respirable fibres. Fibre-specific differences between asbestos and man-made fibres. Exp Lung Res 1996;22:133-48.

11 Wylie AG, Skinner HCW, Marsh J, et al. Mineralogical features associated with cytotoxic and proliferative effects of fibrous talc and asbestos on rodent tracheal epithelial and pleural mesothelial cells. Toxicol Appl Pharmacol 1997;147: 143-50.

12 Luys M-J, De Roy G, Vansant EF, et al. Characteristics of asbestos minerals. Fournal of the Chemical Society Faraday Transactions I 1982;78:3561-71.

13 Kamp DW, Graceffa P, Pryor WA, et al. The role of free radicals in asbestos-induced diseases. Free Radic Biol Med 1992;12:293-315.

14 Fubini B, Mollo L, Giamello E. Free radical generation at the solid/liquid interface in iron containing minerals. Free Radic Res 1995;23:593-614.

15 Fubini B, Mollo L. Role of iron in the reactivity of mineral fibres. Toxicol Lett 1995;82/83:951-60.

16 Gold J, Amandusson H, Krozer A, et al. Chemical characterization and reactivity of iron chelator-treated amphibole asbestos. Environ Health Perspect 1997; 105(suppl 5):1021-30.

17 Ghio AJ, Kennedy TP, Stonehuerner JG, et al. DNA strand breaks following in vitro exposure to asbestos increase with surface-complexed $\left[\mathrm{Fe}^{3+}\right]$. Arch Biochem Biophys 1994;311: $13-18$.

18 Valerio F, Balducci D. Qualitative and quantitative evaluation of chrysotile and crocidolite fibres with infrared spectrophotometry: application to asbestos-cement products. IARC Sci Publ 1989;90:197-204

19 Dumitru-Stanescu R, Mandravel C, Bercu C. Infrared and NMR studies of some surface properties of asbestosalbumin interactions. Analyst 1994;119:689-91.

20 Wagner JC, Skidmore JW, Hill RJ, et al. Erionite exposure and mesothelioma in rats. Br $\mathcal{F}$ Cancer 1985;51:727-30.

21 Monchaux G, Bignon J, Jaurand MC, et al. Mesotheliomas in rats following inoculation with acid-leached chrysotile asbestos and other mineral fibers. Carcinogenesis 1981;2: 229-36.

22 Brown DM, Roberts NK, Donaldson K. Effect of coating with lung lining fluid on the ability of fibres to produce a respiratory burst in rat alveolar macrophages. Toxicology In Vitro 1998:15-24.

23 Scheule RK, Holian A. IgG specifically enhances chrysotile asbestos-stimulated superoxide anion production by the alveolar macrophage. Am $\mathcal{F}$ Respir Cell Mol Biol 1989;1: $313-18$

24 Bellon P, Averback RS. Non-equilibrium roughening of interfaces in crystals under shear: Application to ball milling. Physical Review Letters 1995;74:1819-22.

25 Shen Z, Parker VD, Aust E. Mediated, thin-layer cell, coulometric determination of redox-active iron on the surface of asbestos fibres. Anal Chem 1995;67:307-11. 